\title{
Thermal decomposition behavior of water hyacinth (eichhornia crassipes) under an inert atmosphere
}

\author{
Sukarni Sukarni ${ }^{1, *}$, Aloon Eko Widiono ${ }^{1}$, Sumarli Sumarli ${ }^{1}$, Retno Wulandari ${ }^{1}$, Imam Muda \\ Nauri ${ }^{1}$, and Avita Ayu Permanasari ${ }^{1}$ \\ ${ }^{1}$ Center for Renewable and Sustainable Energy Engineering, Departement of Mechanical \\ Engineering, State University of Malang, 65145 Malang, Indonesia
}

\begin{abstract}
Thermogravimetric analysis experiment to understand thermal decomposition behavior of water hyacinth during the pyrolysis has been performed. Water hyacinth was taken randomly from 2 places, i.e., Selorejo and Sengguruh Dam, district of Malang, Indonesia. Those raw materials were thoroughly cleaned by using the water, then cut and dried in an oven with a temperature range of $80-90^{\circ} \mathrm{C}$ for 6 hours. Subsequently, the dried samples were crushed and then filtered to a mesh size of 60 . Thermal behavior of the sample was observed through the instrumentality of thermal analyzer at a constant heating rate of $10^{\circ} \mathrm{C} / \mathrm{min}$ with a nitrogen flow rate of $100 \mathrm{ml} / \mathrm{min}$ and a temperature range of $25-1000^{\circ} \mathrm{C}$. The kinetics of active pyrolysis zone were evaluated by Coats-Redfern integral method. The thermogravimetric test results show that the water hyacinth biomass decomposed into four stages during the pyrolysis process. The kinetic parameters in term of activation energy $(E)$, logarithmic frequency factor $(\log A)$ and reaction order $(n)$ were $60.74 \mathrm{~kJ} / \mathrm{mol}, 4.77 / \mathrm{min}$ and 1.9 , respectively.
\end{abstract}

\section{Introduction}

The increased consumption of energy in Indonesia occurs annually from 2000 to 2014, except in 2005and 2006. The average annual of such increase over the period 2000-2014 is 3.99\% per annum, from 555.88 million Barrel Oil Equivalent (BOE) in 2000 to 961.39 million BOE in 2014. Final energy consumption by the type during the period 2000-2014 is still dominated by fossil fuel oil [1]. In contrast to the increasing energy demand, petroleum reserves continue to decrease, and it is predicted that it will be exhausted within 12 years [2]. Thus discovering alternative energy sources for substituting or replacing the entirety of fossil-based energy is a very critical obligation to do to avoid endangered life [3, 4]. Biomass is one of the most abundant alternative sources of energy in Indonesia [5, 6]. One of the biomass that a very fast growing is water hyacinth (WH). WH, which is often regarded as a weed, to be a daunting challenge to examine its practicability as an alternative energy source for future life.

The potential of WH from the biomass overabundance point of view is enormous. Under appropriate environmental conditions, WH may double its biomass through asexual

\footnotetext{
* Corresponding author: sukarni.ft@um.ac.id
} 
reproduction within two weeks; ten WH plants can produce 655,360 new plants in eight months, and they can cover the water surface by about half a hectare [7]. The WH's excessive amount and its expansive growthresulted in to interfere with shipping, irrigation and electricity generation [8]. In Selorejo dam, Malang, East Java, Indonesia, 100 hectares of the total reservoir area of 650 hectares is covered by WH. In fact, this reservoir with a maximum water capacity of 62 million $\mathrm{m}^{3}$ is used to drive a turbine's power plant of 45 million $\mathrm{kWh}$ per year. Moreover, it also irrigates agricultural areas of 5,700 hectares [9]. Therefore, assessing the potential of $\mathrm{WH}$ as a fuel raw material will be a very critical task in order to overcome the problem of overabundance of $\mathrm{WH}$ and for discovering alternative and renewable energy sources.

The thermochemical conversion process of biomass into energy can be realized by four modes: direct combustion, pyrolysis, liquefaction, and gasification. The pyrolysis technique is a promising mode for the conversion of biomass into gaseous fuel, bio-oil and biochar [10, 11]. Understanding the thermal behavior of biomass thoroughly during the pyrolysis conversion process is essential in order to be able to design suitable reactor and temperature control systems, resulting in optimal pyrolysis products. For this purpose, thermogravimetric (TG) analysis come to be a technique which is generally used by researchers. TG is a technique in which the sample is heated at a prescribed programmed temperature and the decrease in sample mass as a function of temperature or time is monitored [12]. Derivative thermogravimetric (DTG) is a profile that describes the rate of decrease in sample mass, the first derivative of the TG graph. From the DTG profile, it is possible to discover the mass loss and mass loss rate occurring at the given temperature during the thermal degradation process. Differential scanning calorimetry (DSC) and differential thermal analysis (DTA) are two closely related techniques in which changes in temperature differences between samples and reference samples are analyzed when samples are subjected to temperature changes, and thermal effects in the material are observed. By using DSC or DTA, any event where the thermal reaction either absorbs (endothermic) or releases heat (exothermic) is able to observe [12]. Thus the overall TG data obtained can be used to predict the degradation mechanism and evaluate the reaction kinetics during the pyrolysis process. Good understanding of the kinetics of the thermal decomposition of biomass and subsequent reactions have a very significant role as a basis for designing and modeling pyrolysis reactor systems [3, 13]. Moreover, the study of kinetic pyrolysis of biomass is also critical because pyrolysis is the first step of the combustion and gasification processes [14].

In this study, the pyrolysis experiment through the instrumentality of TG is performed to identify thermo-chemical characteristic data from WH biomass. Kinetics of WH pyrolysis reaction is also studied at a single heating rate of $10^{\circ} \mathrm{C} / \mathrm{min}$. Estimation of kinetic parameters is conducted by using the Coats-Redfern method.

\section{Materials and method}

\subsection{Materials preparation}

WH samples were taken randomly from both dam of Selorejo and Sengguruh, district of Malang, Indonesia. WH raw material was cleaned by using water and then cut before being dried in an oven in the temperature ranging from $80-90{ }^{\circ} \mathrm{C}$ for 6 hours. Dried WH was then crushed into powder and filtered by using a 60 mesh strainer. The WH powder was then stored in a tightly sealed bottle. Physical and chemical properties of the sample, as shown in Table 1, were referenced from [15]. 


\subsection{Thermogravimetric test}

The thermal behavior of WH biomass was studied by using a thermal analyzer (METTLER TOLEDO TGA/DSC1) of which nitrogen carrier gas flowed at a constant rate of $100 \mathrm{ml} / \mathrm{min}$. Approximately $6 \mathrm{mg}$ of sample was placed on crucible before being put into the furnace and heated at a constant heating rate of $10{ }^{\circ} \mathrm{C} / \mathrm{min}$ from 25 to $1000{ }^{\circ} \mathrm{C}$. During the pyrolysis process, the decrease in sample mass was recorded continuously as a function of temperature and time by using a computer working in coordination with the furnace. Simultaneously TG, DTG and DSC graphs were obtained during the experimental process.

\subsection{Kinetics method}

The thermal degradation of organic biomass components during the pyrolysis process could be described as [16-18]:

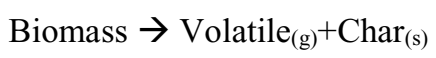

From the TG graph, a number of components undergoing thermal degradation were expressed as conversions (lost mass fractions), , as the following:

where:

$$
\alpha=\frac{m_{i}-m_{t}}{m_{i}-m_{f}}
$$

$m_{i}$ is the initial mass of the sample;

$m_{t}$ is the actual mass of the sample at time $t$;

$m_{f}$ is the final mass that refers to the end of the mass event of interest

$$
\frac{d \alpha}{d t}=k(T) f(\alpha)=A e^{\frac{-E}{R T}} f(\alpha)
$$

in which

$t$ is the time (minute),

$k$ is the constant of temperature-dependent rate,

$f$ is the function of conversion of temperature-independent,

$A$ is the frequency factor $\left(\mathrm{s}^{-1}\right)$,

$E$ is the activation energy $(\mathrm{kJ} / \mathrm{mol})$,

$R$ is the universal gas constant $(\mathrm{kJ} / \mathrm{mol} \mathrm{K})$,

$T$ is the absolute reaction temperature $(\mathrm{K})$.

In non-isothermal reactions, the heating rate can be expressed as $\beta=d T / d t$. The equation (2) is substituted by $d t=d T / \beta$ and then by determining the model of the $n$th order reaction, the following equation of non-isothermal reaction kinetics is obtained:

$$
\frac{d \alpha}{(1-a)^{n}}=\frac{A}{\beta} e^{\frac{-E}{R T}} d T
$$

Equation (3) is the basis for determining kinetics parameters through the use of the fitting model of the biomass which undergoing thermochemical conversion [19]. 


\section{Results and Discussion}

\subsection{Thermal behaviors}

Table 1 shows the material properties of WH. Figure 1 shows graphs of TG, DTG, and DSC of WH pyrolysis at a heating rate of $10^{\circ} \mathrm{C} / \mathrm{min}$. Based on Figure 1 , it was clearly recognized that during thepyrolysis from room temperature up to $1000^{\circ} \mathrm{C}$, the $\mathrm{WH}$ was decomposed into four stages.

Table 1. Material properties of WH, referred from [15].

\begin{tabular}{|c|c|c|c|c|}
\hline \multicolumn{2}{|c|}{$\begin{array}{c}\text { Chemical elements } \\
\text { (wt,\%) }\end{array}$} & \multicolumn{2}{|c|}{$\begin{array}{c}\text { Physical properties } \\
\text { (wt,\%) }\end{array}$} & $\begin{array}{c}\text { HHV } \\
\text { (MJ/kg) }\end{array}$ \\
\hline $\begin{array}{l}\mathrm{C} \\
\mathrm{O} \\
\mathrm{Na} \\
\mathrm{Mg} \\
\mathrm{Al} \\
\mathrm{Zr} \\
\mathrm{Cl} \\
\mathrm{K} \\
\mathrm{Ca} \\
\mathrm{Si} \\
\mathrm{Ti} \\
\mathrm{Fe}\end{array}$ & $\begin{array}{l}14.4 \pm 6.81 \\
49.5 \pm 6.71 \\
0.58 \pm 0.40 \\
1.96 \pm 1.04 \\
2.32 \pm 1.71 \\
2.24 \pm 1.33 \\
5.58 \pm 1.94 \\
8.26 \pm 2.62 \\
4.73 \pm 0.63 \\
5.33 \pm 4.52 \\
0.27 \pm 0.27 \\
4.71 \pm 4.32\end{array}$ & $\begin{array}{c}\text { Moisture } \\
\text { Volatile matter Fixed } \\
\text { carbon } \\
\text { Ash }\end{array}$ & $\begin{array}{l}4.9(\mathrm{ar}) \\
64.4(\mathrm{db}) \\
14.5(\mathrm{db}) \\
21.1(\mathrm{db})\end{array}$ & 14.46 \\
\hline
\end{tabular}

ar: as received, db: dry basis.

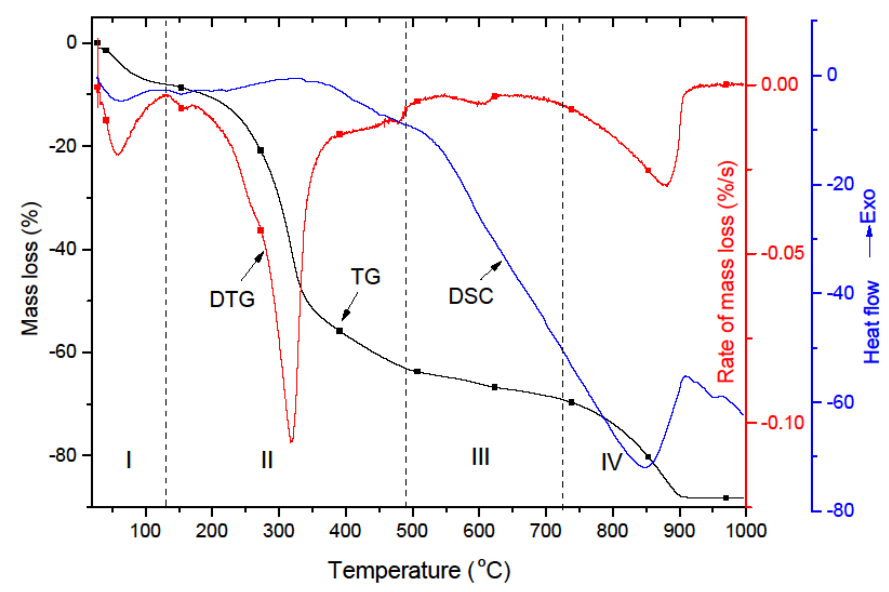

Fig. 1. TG, DTG and DSC curves of WH pyrolysis at $10{ }^{\circ} \mathrm{C} / \mathrm{min}$.

Stage I started at $25^{\circ} \mathrm{C}$ and finished at a temperature of $128^{\circ} \mathrm{C}$. The stage corresponded to the release of moisture and the light volatile compound, characterized by the appearance of the first basin on the DTG curve. On the DSC curve, the emergence of the basin in the stage I was also notified, indicating that the reaction of moisture release was endothermic. The moisture content in biomass affected the physical properties and the quality of liquid which resulted in pyrolysis, where the dry raw material produces a very viscous oil, especially at higher reaction temperatures [20]. However, less attention was given by researchers at this 
stage, since the biomass used in pyrolysis was generally a dry matter and was not a raw material [21]. In this study, decreasing sample mass in stage I was about $7 \%$, while the proximate test result showed that the water content was $4.9 \%$. This fact then reinforced the analysis that the thermal effects of stage I not only did cause moisture release but also degraded some organic components before being released into light volatiles.

Stage II occurred in the temperature range of $128-492{ }^{\circ} \mathrm{C}$. This stage was also referred to as the active pyrolysis stage, a significant degradation stage of the organic component, in which most of the mass was decomposed and released to become volatile [22]. This phenomenon was indicated by the appearance of a sharp slope on the TG curve and the very deep basin of the DTG curve. A total of $57 \%$ of the WH mass was decomposed at this stage.

Stage III presented in the temperature range of $492-724{ }^{\circ} \mathrm{C}$. This stage was characterized by a TG curve tending to be horizontal, and there was only a slight slope along with the rise in the temperature. It indicated that carbon in biochar was continuously decomposed at a very slow rate with little loss of mass. The DSC curve at this stage indicated a very sharp slope, indicating that thermal degradation at this stage absorbed a significant amount of heat.

From the Figure 1 it was also known that with the completion of stage III at temperature $724^{\circ} \mathrm{C}$, a sharp slope of the TG curve and a basin of DTG curve emerged in stage IV. It probably due to further decomposition of carbon components and thermal decomposition of inorganic components from the WH biomass

\subsection{Calculation of kinetic parameters}

The determination of kinetic parameters in this study was conducted by assuming that the thermal degradation reaction of WH pyrolysis occurred at a certain temperature zone as a single step reaction of $n$th order. Thus the reaction rate of pyrolysis could be expressed by equation (3). In this study, a kinetic analysis was performed on the active pyrolysis zone only. Properties of the active pyrolysis zone, at stage II, were presented in the following Table 2.

Table 2. Properties of $\mathrm{WH}$ active pyrolisis zone at $10^{\circ} \mathrm{C} / \mathrm{min}$.

\begin{tabular}{|c|c|c|c|c|}
\hline \multicolumn{5}{|c|}{ Properties } \\
\hline $\mathrm{T}_{\mathrm{i}}\left({ }^{\circ} \mathrm{C}\right)$ & $\mathrm{T}_{\mathrm{f}}\left({ }^{\circ} \mathrm{C}\right)$ & $\mathrm{T}_{\mathrm{m}}\left({ }^{\circ} \mathrm{C}\right)$ & $\mathrm{M}_{\mathrm{m}}\left({ }^{\circ} \mathrm{C}\right)$ & Mass loss $(\%)$ \\
\hline 128 & 492 & 318 & 0.106 & 57 \\
\hline
\end{tabular}

Under the Coats-Redfern method, equation (3) was integrated and produced an exponential integral. The completion of this integral was done by using the Taylor series approach [19]. The linearization of the equation yielded the final equation as follows:

$$
\ln g(\alpha)=-\frac{E}{R T}+\ln \frac{A R}{\beta E}
$$

where:

$$
\begin{aligned}
& \text { if } n=1 \text { then } g(\alpha)=-(\ln (1-\alpha)) / T^{2} \\
& \text { if } n \neq 1 \text { then } g(\alpha)=\left(1-(1-\alpha)^{(1-n)}\right) /\left((1-n) T^{2}\right)
\end{aligned}
$$

From the linear equation (4) subsequently plots between $\ln g(\alpha)$ with $1 / T$ at the specified $n$ range were drawn. The determination of the most suitable reaction order $n$ was indicated by the value of the correlation coefficient $\left(R^{2}\right)$ closest to 1 , so the linear regression of the plot between $\ln g(\alpha)$ and $1 / T$ resulted in a straight line. To get the right $n$ value, the steps taken were: first, the various values of $n$ was chosen and then apply to the plot between 
$\ln g(\alpha)$ with $1 / T$ so that the value of $R^{2}$ from each plot was gained; second, plot between $R^{2}$ and $n$ so that the right $n$ value was in correlation with the highest $R^{2}$ value on the curve. The value of $n$ obtained in the second step, then, was used to calculate the $\ln g(\alpha)$ value of the selected $\alpha$, so that finally the plot between $\ln g(\alpha)$ with $1 / T$ could be depicted in relation to $T$ at a corresponding $\alpha$. The value of activation energy and frequency factor in the active pyrolysis zone were respectively obtained from the slope and intercept of the last plot.

In this study, initially any $n$ was selected in the range of 0.5-4.5 and then it was applied to calculate $\ln g(\alpha)$ in the conversion range $(\alpha)$ between $0.05-0.95$. The plot between $\ln g(\alpha)$ and $1 / T$ at each $n$ produced $R^{2}$ and then the $R^{2}-n$ curve was obtained as shown in Figure 2. From the Figure 2, it was recognized that $R^{2}=0.977$ (the highest) corresponded with $n=$ 1.9. The $n$ value was then used for the evaluation of kinetics parameters in the active pyrolysis zone of WH biomass. The final plot between $\ln g(\alpha)$ and $1 / T$ was shown in Figure 3 . The kinetics parameters of the active pyrolysis zone of WH were shown in Table 3.

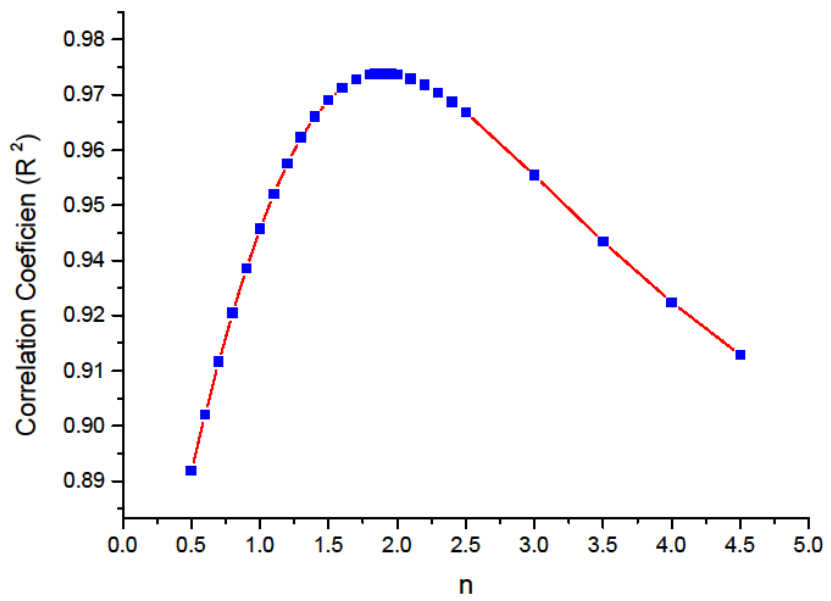

Fig 2. The $R^{2}-n$ curve produced by the Coats-Redfern method.

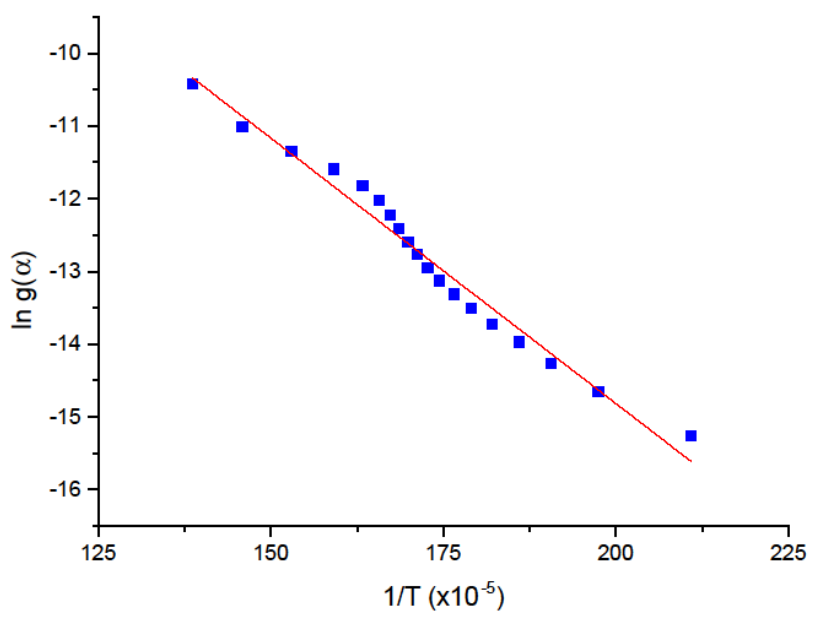

Fig. 3. Linear regression of plot $\ln g(\alpha)$ with $1 / T$. 
Table 3. The kinetics parameters of active pyrolisis zone of WH.

\begin{tabular}{|c|l|c|c|c|c|}
\hline $\boldsymbol{\beta}\left({ }^{\mathbf{0}} \mathbf{C} / \mathbf{m i n}\right)$ & $\begin{array}{l}\text { Trendline } \\
\text { equation }\end{array}$ & \multirow{2}{*}{$\boldsymbol{R}^{\mathbf{2}}$} & \multicolumn{3}{|c|}{ Kinetics parameters } \\
\cline { 4 - 6 } & & & $\boldsymbol{E} \mathbf{( k J / m o l )}$ & $\begin{array}{c}\log \boldsymbol{A} \\
(\mathbf{1} / \mathbf{m i n})\end{array}$ & $\boldsymbol{n}$ \\
\hline 10 & $\begin{array}{l}y=-7306.08 x \\
-0.209\end{array}$ & 0.977 & 60.74 & 4.77 & 1.9 \\
\hline
\end{tabular}

The magnitude of the activation energy in a reaction represented the minimal amount of energy required to overcome the obstacles before a chemical reaction is created, and the higher activation energy value was, the more difficult reaction would be [3]. From Table 3 it is known that the activation energy of WH pyrolysis was $60.74 \mathrm{~kJ} / \mathrm{mol}$. This value was lower than the activation energy of the pyrolysis of bagasse, $87.9 \mathrm{~kJ} / \mathrm{mol}$ [23] and agro-industrial waste, between 133-275 kJ/mol [24]. However, the activation energy value of WH pyrolysis was higher than that of the date palm biomass, where the activation energy of pyrolysis of various parts of date palm trees was less than $45 \mathrm{~kJ} / \mathrm{mol}$ [17]. It suggested that WH biomass was more reactive during thermal processes in the active pyrolysis zone than bagasse and agro-industrial waste, but it was still lower in reactivity compared with date biomass.

\section{Conclusion}

The thermal characteristic and reaction kinetics of WH pyrolysis was investigated. During the pyrolysis process, WH was degraded into four stages with active pyrolysis zone occurring in stage II, where nearly $60 \%$ of the WH mass was volatilized. The activation energy in active pyrolysis zone of the $\mathrm{WH}$ which evaluated by Coats-Redfern method was $60.74 \mathrm{~kJ} / \mathrm{mol}$.

\section{Acknowledgments}

This research is funded by the State Non-Tax Revenue (PNBP) of State University of Malang (UM) Year 2018 with grant number 2.3.155/UN32.14/LT/2018. Therefore the authors would like to his/her gratitude to UM for the support of the research fund.

\section{References}

1. Ministry of Energy and Mineral Resources of Indonesia, Handbook of Energy and Economic Statistics of Indonesia 2015 (2015).

2. BPPT, Indonesia Energy Outlook 2016 (2016).

3. Sukarni, Sudjito, N. Hamidi, U. Yanuhar, I. N. G. Wardana, Front. Energy. 9, 125-133 (2015).

4. Sukarni, Sumarli, P. Puspitasari, H. Suryanto, R. F. Wati, in AIP Conference Proceedings (2017), vol. 1887, p. 020066.

5. Sukarni, Sudjito, N. Hamidi, U. Yanuhar, I. N. G. Wardana, Int. J. Energy Environ. Eng. 5, 279-290 (2014).

6. S. Sukarni et al., J. Appl. Res. Technol. 16, 53-66 (2018).

7. D. Güereña, H. Neufeldt, J. Berazneva, S. Duby, Sustain. Prod. Consum. 3, 59-69 (2015).

8. S. Rezania et al., Int. J. Phytoremediation. 18, 679-685 (2016).

9. tempo.co, (2016), (available at https://nasional.tempo.co/read/470941/eceng-gondokdi-waduk-selorejo-terus-meluas). 
10. L. Zhou, H. Yang, H. Wu, M. Wang, D. Cheng, Fuel Process. Technol. 106, 385-391 (2013).

11. I. Ali, H. Bahaitham, R. Naibulharam, Bioresour. Technol. 235 (2017), doi:10.1016/j.biortech.2017.03.089.

12. S. Sukarni, in AIP Conference Proceedings (2016), vol. 1778, p. 020003.

13. A. Agrawal, S. Chakraborty, Bioresour. Technol. 128, 72-80 (2013).

14. T. Mani, P. Murugan, J. Abedi, N. Mahinpey, Chem. Eng. Res. Des. 88, 952-958 (2010).

15. S. Sukarni et al., in International Conference on Condensed Matters and Advanced Materials (IC2MAM 2018), p. (to be published).

16. H. Chen, W. Zhao, N. Liu, Energy and Fuels. 25, 797-803 (2011).

17. H. H. Sait, A. Hussain, A. A. Salema, F. N. Ani, Bioresour. Technol. 118, 382-389 (2012).

18. J. M. Jones, M. Pourkashanian, A. Williams, D. Hainsworth, Renew. Energy. 19, 229$234(2000)$.

19. K. Açikalin, J. Therm. Anal. Calorim. 109, 227-235 (2012).

20. A. Demirbas, J. Anal. Appl. Pyrolysis. 71, 803-815 (2004).

21. D. Chen, Y. Zheng, X. Zhu, Bioresour. Technol. 131, 40-46 (2013).

22. Q. V. Bach, W. H. Chen, Bioresour. Technol. 246, 88-100 (2017).

23. J. E. White, W. J. Catallo, B. L. Legendre, J. Anal. Appl. Pyrolysis. 91, 1-33 (2011).

24. A. Fernandez, C. Palacios, M. Echegaray, G. Mazza, R. Rodriguez, Combust. Sci. Technol. 190, 114-135 (2018). 